\title{
Effects of Portabella mushrooms on collagen-induced arthritis, inflammatory cytokines, and body composition in dilute brown non-agouti (DBA1) mice
}

\author{
Sandra Peterson ${ }^{1}$, Edralin A. Lucas ${ }^{1}$, Djibril Traore ${ }^{1}$, Lawrance Christopher ${ }^{1}$, Christine \\ French $^{1}$, Stephen L. Clarke ${ }^{1}$, Stanley A. Lightfoot ${ }^{2}$, Brenda J. Smith ${ }^{1}$, Solo Kuvibidila ${ }^{1,3}$ \\ ${ }^{1}$ Department of Nutritional Sciences, College of Human Environmental Sciences, Oklahoma \\ State University, Stillwater; OK 74078, USA; ${ }^{2}$ VA Hospital, Oklahoma University Health \\ Sciences Center, Oklahoma City, OK, 73104, USA; ${ }^{3}$ The Research Institute for Children's \\ Hospital, New Orleans, LA, 70118, USA.
}

Corresponding Author: Solo Kuvibidila, PhD, C/o Brenda J. Smith, Ph.D.; Department of Nutritional Sciences Oklahoma State University, College of Environmental Sciences, 420 Human Environmental Sciences; Stillwater, OK 74078

Submission date: July 26, 2011; Acceptance date: September 12, 2011; Publication date: September 17, 2011

Short running title: Portabella and collagen-induced arthritis

\begin{abstract}
:
Background:

Exotic mushrooms have long been used in Asia for treatment and/or prevention of chronic diseases due to their immunomodulatory properties. However, the health benefits of portabella mushrooms (PM) (brown Agaricus bisporous), on collagen-induced arthritis (CIA) and associated complications, (i.e. loss of lean mass, increased fat mass and inflammatory cytokines), have not been previously investigated.
\end{abstract}

\section{Methods:}

We investigated CIA pathogenesis, body composition and plasma levels of IL- 6 , TNF- $\alpha$ and sICAM1 in DBA1 female mice fed either the AIN76 diet or the same diet fortified with 5\% lyophilized PM ( $n=19-20 /$ group). Ten mice/group were immunized with $100 \mu \mathrm{g}$ bovine collagen type II on day 42 of the protocol, followed by $50 \mu \mathrm{g}$ lipopolysaccharides on day 62 , and euthanized on day 73-74. Cytokines were measured by ELISA.

\section{Results:}

Compared to baseline diet, PM had: no protective effect from CIA since all collagen-immunized mice developed severe edema, bone erosion, and mononuclear cell infiltration in paws. In mice with and those without CIA, feeding a PM-fortified diet resulted in higher percent of body fat 
than feeding the baseline diet $(\mathrm{p}<0.05)$. After CIA induction, PM provided the following beneficial effects: (a) a smaller reduction in lean mass and absolute thymus weight; (b) a higher fat mass loss; and (c) lower plasma TNF- $\alpha$ levels ( $\mathrm{p}<0.05$ ). PM-fortification did not alter plasma IL-6 and sICAM1 regardless of CIA status; but it increased in vitro IL-6 secretion by mitogentreated spleen cells.

\section{Conclusion:}

Our data suggest that PM may reduce plasma TNF- $\alpha$, attenuate lean mass loss and thymus atrophy associated with arthritis, and protect spleen cell function assessed by IL-6 secretion. However, PM-fortification did not attenuate overall CIA pathogenesis which may be due to lack of effect on plasma IL-6. Decreased TNF- $\alpha$ without alterations in IL- 6 may reduce the risk of other conditions associated with chronic inflammation such as cardiovascular disease.

Key words: portabella mushrooms, inflammatory cytokines, collagen-induced arthritis, body composition, TNF- $\alpha$, IL-6, thymus, DBA1 mice.

\section{BACKGROUND:}

Rheumatoid arthritis (RA), a common chronic autoimmune inflammatory disease without a known cure, affects $1-2 \%$ of the world's population [1]. The etiology of RA is thought to be multi-factorial and include genetic predisposition, environmental factors, and over-activation of the immune cells (macrophages, T and B-cells) [1-4]. RA is characterized by swelling of joints, infiltration of mononuclear inflammatory cells in the pannus junction, bone erosion, destruction of the cartilage, and increased synovial levels of inflammatory cytokines and adhesion molecules (IL-1, IL-6, IL-10, IL-13, TNF-alpha, ICAM-1, etc.) [5-6]. Increased levels of inflammatory cytokines and activated mononuclear cells are not limited to the pannus junction as they also occur in plasma and bone marrow [4]. As a result of inflammation, changes in bone metabolism (i.e. increased bone resorption and suppressed bone formation) may occur leading to negative effect on bone health.

Available data suggest that patients with RA exhibit alterations in body composition, specifically losses of lean body mass concomitant with increased total body fat which may increase the risk of developing cardiovascular diseases (CVD) [7-8]. In fact, the risk of CVD in RA patients has been reported to be 1.6- to 3.1- fold higher than in the general population [9-11]. Additionally, increased body fat may contribute to increased secretion of pro-inflammatory cytokines such as IL-1 and IL-6 leading to the induction of C-reactive protein (CRP), a risk factor for CVD [11].

Moreover, the pro-inflammatory cytokine TNF- $\alpha$ induces cachexia characterized by the loss of lean body mass [12].. Collagen induced arthritis (CIA) is an experimental animal model used to elucidate some of the mechanisms involved in the pathogenesis of RA [13]. Both CIA and RA share common features, especially those related to increased cytokine production and adhesion molecule expression in the joints, increased plasma cytokines, and weight loss [14]. Because CIA can be induced in some; but not all strains of mice and rats, it has been suggested 
that there is involvement of a genetic component [14]. CIA can be induced by antigens (e.g. bovine collagen type II) leading to secretion of destructive antibodies, or non-antigen compounds (i.e. irritants) which can also induce inflammation [12,15].

Due to its inflammatory nature, RA management involves the suppression of pro inflammatory cytokines. Several compounds that modulate either TNF- $\alpha$ or IL-6 signaling have been examined in clinical studies and have yielded some benefits; however they also induce less desirable side effects $[3,16]$. For example, anti-TNF- $\alpha$ monoclonal antibodies (infliximab) have been reported to increase the risk of infections, sepsis, and tuberculosis, along with altered myelin metabolism [3]. Increased risk of infections is not surprising because TNF- $\alpha$ is involved in pathogen killing [17]. Anti-IL-6 antibodies and anti-IL-6 receptor antagonists have also been tested for their efficacy to alter the course of RA and/or CIA [16]. However, these drugs can also affect the overall IL-6 function including hepatic CRP biosynthesis, an acute phase protein involved in extracellular pathogen killing. As a result of these side effects, alternative compounds, such as the use of natural foods with bioactive compounds that modulate inflammatory markers are being sought in the management of RA.

Certain exotic mushrooms such as shiitake and maitake have long been used as medicinal foods in many Asian countries. As medicine, they are thought to prevent chronic diseases such as cancer and infection [18-20]. The mechanisms involved in the prevention of chronic diseases are just being elucidated and they include modulation of both innate and adaptive immunity [19].

Unlike the rich literature that exists on the anti-cancer, anti-viral, and anti-bacterial properties of mushrooms, only a handful of studies have been conducted that examined the use of mushrooms in arthritis prevention and/or treatment. In 2003, Kim et al reported that proeoglycan-rich extracts from Phellinus linteus attenuated CIA severity in DBA1when given in the pre- and post- CII booster period [21]. In parallel to reduced CIA severity, plasma anti-CII antibodies were also reduced by the extracts. In contrast to Phellinus linteus, oral administration of maitake (Grifola frondosa) polysaccharide provided no benefits on CIA severity [22]. In fact, the extracts increased arthritis indices by 3-4 fold compared to mice that received saline.

Recently, we observed that white button mushroom (WBM)-fortified diet tended to reduce the incidence of CIA, plasma levels of TNF- $\alpha$ and IL-6, and to attenuate the severity of mononuclear cells in the joints in DBA female mice [23]. Although portabella mushrooms (PM) are simply more than brown and more mature Arigacus Bisporus, it is uncertain to the degree that they will provide the same health benefit on CIA pathogenesis as WBM. The goal of this study was to investigate the extent to which PM: (a) modulates CIA pathogenesis (incidence and severity) in DBA1 mice; (b) alter body composition (distribution of lean and fat mass) associated with development of arthritis; and (c) modulate plasma concentration of inflammatory cytokines in mice with and without CIA.

\section{MATERIALS AND METHODS:}

\section{Chemicals and Reagents}

Reagents were purchased from the following suppliers: Sigma (St Louis, MO): E. Coli lipopolysaccharides (LPS), complete Freund's adjuvant; Chondrex Inc. (Redmond, WA): trachea 
bovine type II collagen; Teklad (Indianapolis, IN): AIN76 diet and the same diet fortified with $5 \%$ lyophilized portabella mushrooms; R\&D System (Minneapolis, MN): IL-6, TNF- $\alpha$, and sICAM-1 assay kits; GIBCO (Grand Island, NY).

\section{Methods: Animal feeding, induction of CIA, assessment of body composition, and collection of biological specimens}

All procedures were approved by the Institutional Animal Care and Use Committee (IACUC) committee of Oklahoma State University (OSU, Stillwater, OK). Two month old female DBA1 mice $(n=40)$ were purchased from Jackson Laboratories (Bar Harbor, ME). After a $48 \mathrm{~h}$ of acclimation period, mice were randomly assigned (5/cage) to one of the two dietary treatment groups $(n=20)$ Group 1: the AIN76 diet; Group 2: AIN76 fortified with 5\% lyophilized portabella mushrooms. The AIN76 (control) contains all nutrients in adequate amounts to promote growth and good health of rodents [24]. Mice had free access to food and deionized water and were under standard $12 \mathrm{~h}$ light: dark cycle conditions. CIA was induced as previously described [25]. Female mice were used because the prevalence of rheumatoid arthritis is threefold more common in women than in men and the same gender difference is also true in rodents [26-27]. Briefly, after 42 days of feeding their respective diets, mice were weighed, and 10 mice per dietary treatment group were immunized (at the base of the tail) with $100 \mu \mathrm{g}$ of trachea bovine collagen type II dissolved in $0.01 \mathrm{~N}$ acetic acid and complete Freund's adjuvant in 1:1 ratio (total volume of $100 \mu \mathrm{L})$ followed by LPS $(50 \mu \mathrm{g} / 100 \mu \mathrm{L}$ saline [0.85 \% NaCl] 20 days later (62 days of the protocol). The control or unimmunized mice ( $n=10 /$ dietary treatment) received $100 \mu \mathrm{L}$ of the solvent. We used LPS instead of a second dose of collagen type II because it has been shown to induce signs of arthritis (i.e. - paw swelling) in more than $90 \%$ of treated mice within 5 days [27-28]. Mice were immunized at the age of 14 weeks rather than the more usual 8-10 weeks used by other investigators because, in humans, the incidence of rheumatoid arthritis increases with age [27]. Mice continued to have free access to their assigned diets (and water) after collagen and LPS injection and were weighed regularly during this period.

After 11-12 days post-LPS injection, mice were weighed and anesthetized by $\mathrm{CO}_{2}$ inhalation. Body composition was determined using a GE Lunar Piximus (Fitchburg, WI). The PIXImus uses low energy X-rays to produce images then uses software to estimate the density and weight of lean tissue, fat tissue, and bone. The anesthetized mice were placed on a plastic tray in the prone position with the limbs spread apart and tail positioned on the side with tape. The head of each mouse was excluded from analysis. The machine was calibrated daily using a plastic "mouse phantom" provided by the manufacturer.

Blood samples were collected from the retro-orbital plexus into micro-centrifuge tubes containing $100 \mathrm{U}$ heparin, centrifuged at $14,000 \mathrm{rpm}$ at room temperature, and plasma was collected and immediately frozen at $-80^{\circ} \mathrm{C}$ until used for various measurements. All four paws and organs (heart, kidneys, lungs, livers, and thymus) were removed, weighed, and immediately transferred to formalin for histopathological studies.

\section{Histopathology of the paws}


After fixing in 10\% buffered-formalin solution followed by decalcification in 5\% formic acid, paws were embedded in paraffin. Thin sections $(5 \mu \mathrm{m})$ were cut and stained with hematoxilin/eosin. Bone erosion and inflammation as indicated by mononuclear cell infiltration in the paws of collagen-treated and untreated mice were scored as described by Joosten et al [25] by two blinded pathologists (co-authors SL \& LC). The severity of inflammation was defined as $0,1,2$, and 3 corresponding to none, mild, moderate, and severe inflammation, respectively. The degree of bone erosion was defined also on a scale $0-3$, with 0 corresponding to normal bone and 3 being fully eroded cortical bone [25].

\section{In vitro secretion of IL-6 and TNF- $\alpha$ by spleen cells}

Single cell suspensions were prepared from spleens by standard techniques in phosphate buffered saline supplemented with $2.5 \%$ FCS, $100 \mu \mathrm{g} / \mathrm{ml}$ streptomycin and 100 units $/ \mathrm{ml}$ penicillin [29]. Viable spleen cells, $2 \times 10^{6}$ were mixed with either culture medium, $2.5 \mu \mathrm{g}$ concanavalin (Con) A, or $2.5 \mu \mathrm{g}$ LPS in $1 \mathrm{ml}$ culture medium that contained per liter of RPMI1640: 25 mmol HEPES, $100 \mathrm{mg}$ streptomycin, 1 x 105 units penicillin, 2 mmol L-glutamine, 1 mmol sodium pyruvate, $0.1 \mathrm{mmol}$ nonessential amino acids, and $50 \mu \mathrm{mol}$ of $\beta$-mercaptoethanol. Cells were transferred to 24-well plates and were incubated at $37^{\circ} \mathrm{C}, 5 \% \mathrm{CO}_{2}$, in a humidified atmosphere (Thermo [NAPCO], Fisher Scientific, Marietta, OH) for $48 \mathrm{~h}$. Plates were centrifuged at $1000 \mathrm{rpm}, 4^{\circ} \mathrm{C}$, for $10 \mathrm{~min}$. Supernatant were collected and immediately frozen at $-80^{\circ} \mathrm{C}$ until used for the measurement of cytokines.

\section{Cell proliferation by MTT test}

To determine whether changes, if any, in in vitro cytokine secretion by spleen cells from mice fed PM-fortified diet were due to altered cell proliferation, microcultures were also prepared in parallel to macrocultures. Viable nucleated spleen cells, 1 x 106 were mixed with either LPS, Con A $(2.5 \mu \mathrm{g} / \mathrm{ml})$, or culture medium. Two hundred microliters were transferred to 96-well plates in triplicate and the plates were incubated for $44 \mathrm{~h}$ at $37^{\circ} \mathrm{C}, 5 \% \mathrm{CO} 2$, in a humidified incubator. Fifty microliters of tetrazolium bromide salt $(5 \mathrm{mg} / \mathrm{ml})$ were then added to each well and the plates were further incubated for $4 \mathrm{~h}$. The reaction was stopped by the addition of $50 \mu \mathrm{l}$ of $0.08 \mathrm{~N} \mathrm{HCl}$ - isopropanol solution and the optical density (OD) was analyzed using a plate reader at $570 \mathrm{~nm}$ with a correction wavelength of $630 \mathrm{~nm}$. The rationale of this assay is that viable cells metabolize tetrazolium bromide to blue crystals (or formazan); dead cells do not.

\section{Cytokines and SICAM-1 assay}

Three markers of inflammation which included IL-6, TNF- $\alpha$, and sICAM1, were measured in plasma by ELISA with commercial kits (R\&D) according to the manufacturer's specifications. IL- 6 and TNF- $\alpha$ were also measured in the supernatants of activated spleen cells by ELISA.

\section{Statistical analysis}

Analysis of variance (ANOVA) and/or Student's $t$ tests, $\chi^{2}$ test were performed by Microstatistical program (Microsoft Inc, Indianapolis, IN). Pearson's correlation coefficients and multiple regression analysis were also calculated. The level of significance was set at $\alpha=0.05$. 


\section{RESULTS:}

\section{Growth rate and organ weights}

One mouse fed PM-fortified diet died after LPS injection and therefore was excluded from the analysis. At the beginning of the feeding period, there was no significant difference in mean body weights between mice fed control and PM-fortified diets (Figure 1). However, by treatment day 42 of dietary treatment (age 84 days) and the period following immunization with collagen, LPS, or solvent, the mean body weights of mice fed PM-fortified diet were higher than those fed control diet. The differences were significant at some but not all time points (Figure 1, p <0.05). Collagen administration alone did not have a significant impact on mean body weights in either dietary treatment group; however, as expected, LPS administration decreased mean body weights by $15.0 \%$ and $21.3 \%$ ( $\mathrm{p}<0.05)$ in mice fed the control and fortified diets, respectively (Figure 1).

\section{Food intake}

Mean food intake tended to be about 10\% higher in mice fed PM-fortified diet than in those fed the control diet and the differences were statistically significant (Figure 2, $\mathrm{p}<0.05$ ).

Administration of collagen, solvent (acetic acid/Freund's adjuvant), LPS, and saline resulted in small drop of food intake within the following $48 \mathrm{~h}$, but then increased above baseline 4 days after LPS $(\mathrm{p}<0.05$

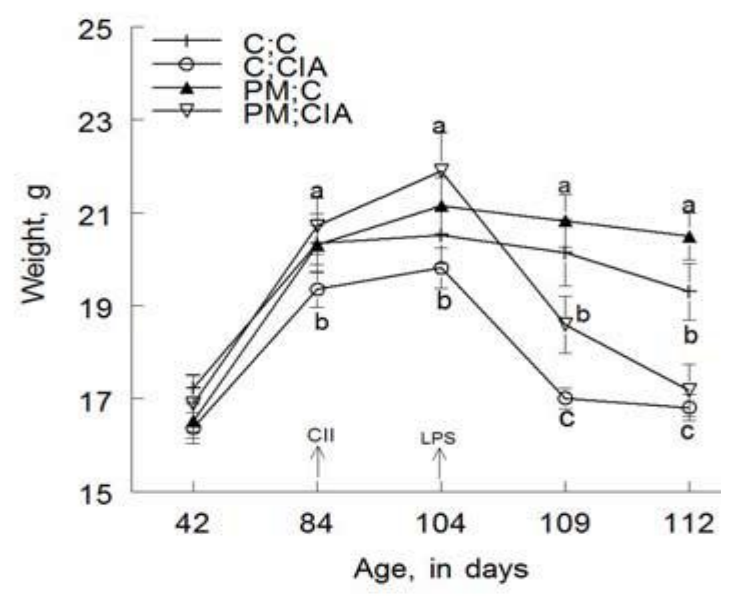

Figure 1. Growth rate of mice fed PM- fortified and control diets as a function of collagen-treatment. Values are means \pm SEM; $n=9-10$ /group. Abbreviations are: $C$; $\mathrm{C}=$ control diet no arthritis; $\mathrm{C}$; CIA = control diet with arthritis; PM; C = PM-fortified diet no arthritis; PM; CIA $=$ PM-fortified diet with arthritis. The arrows $(\uparrow)$ at age 84 and 104 days indicate the time of immunization with collagen (CII) and LPS, respectively. At any time point, means with unlike letters are significantly different; a > $\mathrm{b}>\mathrm{c} ; \mathrm{p}<0.05$

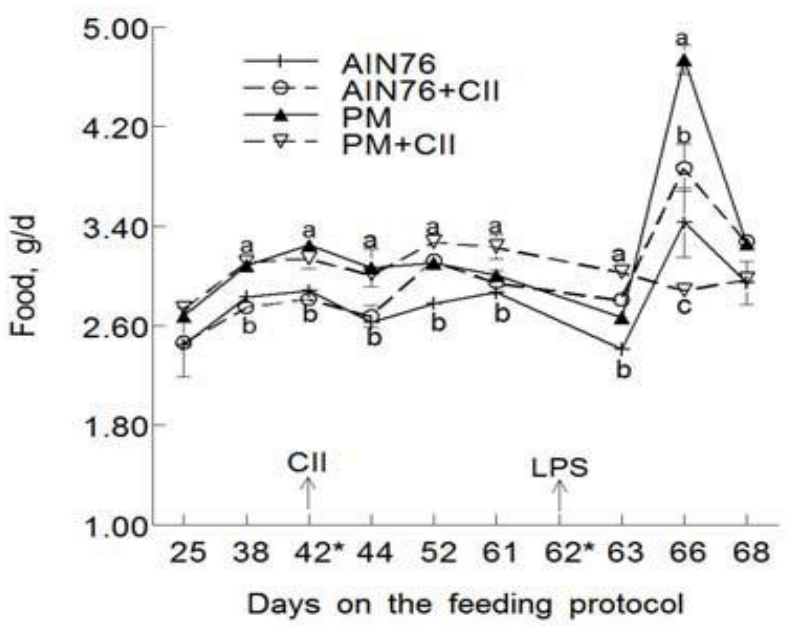

Figure 2. Food intake of mice fed control and PM-fortified diets as a function of collagentreatment. Values are means \pm SEM; $n=9-10$. $42^{*}(\uparrow)$ and $62 *(\uparrow)$ indicate to collagen and LPS administration, respectively. The mean food intakes are for the periods d 1-25, 26-38, 39-42, etc. At any time point, means with unlike letters are significantly different; $\mathrm{a}>\mathrm{b}>\mathrm{c} ; \mathrm{p}<0.05$.

In collagen-untreated mice, PM tended to increase absolute and/or relative mean weights of the spleen and heart ( $\mathrm{p}<0.05$ to $<0.09$ ); but had no significant effect on the liver and kidney weights. 
In unimmunized mice, PM slightly decreased the mean absolute $(\mathrm{p}=0.1)$ and relative $(\mathrm{p}<0.05)$ thymus weights (Table 1). In collagen-treated mice, PM had no significant impact on relative and absolute weights of spleen, kidney and liver. However, mean weights of thymus and heart were slightly higher in mice fed PM-fortified diet than in those fed the control diet $(\mathrm{p}<0.05$ to 0.08 for heart). In both dietary treatment groups, induction of CIA resulted in moderate splenomegaly, thymus atrophy, cardiomegaly, and hepatomegaly $(\mathrm{p}<0.05)$.

\section{Effect of PM on CIA incidence, arthritis index, and bone erosion scores}

PM did not protect mice from CIA. In fact, all of the mice fed control and PM-fortified diets developed severe paw edema. The mean score of mononuclear cell infiltration in affected joints tended to be higher $(\mathrm{p}=0.06)$ in mice fed PM-fortified diet than in those fed control diet (Table 2). Mean pathology scores of bone erosion were also slightly elevated, but not significantly higher in mice fed PM-fortified diet than in those fed the control diet (Table 2). Severe mononuclear cell infiltration in the joints was observed in $66 \%$ of mice fed the PM-fortified diet as compared to only $33 \%$ of mice fed the baseline (AIN-76) diet (Table 2). The proportion of mice with severe bone erosion was also twice as high in mice fed the PM-fortified diet (44\%) than in those fed the control diet $(22 \%)$. However, due to the limited sample size, the differences between both dietary treatment groups were not statistically

Table 1: Effect of portabella mushrooms on organ weights of DBA-1 mice without and with collagen-induced arthritis (CIA).
Control- AIN-76
PM-diet
$\mathrm{p}$

\begin{tabular}{lrcl}
\hline No CIA & & & \\
\hline Spleen, mg & $72.83 \pm 3.06^{*}$ & $85.38 \pm 4.23 \mathbb{I}$ & 0.01 \\
Spleen, mg/g body weight & $3.78 \pm 0.16^{*}$ & $4.19 \pm 0.23 \mathbb{I}$ & 0.08 \\
Thymus, mg & $36.30 \pm 2.81^{*}$ & $31.76 \pm 2.17 \llbracket$ & 0.10 \\
Thymus, mg/g body weight & $1.86 \pm 0.09^{*}$ & $1.54 \pm 0.08 \mathbb{I}$ & 0.01 \\
Liver, mg & $849.8 \pm 53.39$ & $928.4 \pm 41.77 \mathbb{I}$ & 0.11 \\
Liver, mg/g body weight & $43.80 \pm 1.73^{*}$ & $45.2 \pm 1.30 \mathbb{I}$ & 0.26 \\
Heart, mg & $106.7 \pm 10.22^{*}$ & $151.9 \pm 16.35$ & 0.02 \\
Heart, mg/g body weight & $5.80 \pm 0.74^{*}$ & $7.40 \pm 0.82 \mathbb{I}$ & 0.09 \\
Kidney, mg & $275.5 \pm 12.93$ & $288.4 \pm 9.99$ & 0.22 \\
Kidney, mg/g body eight & $14.30 \pm 0.54^{*}$ & $14.10 \pm 0.26 \mathbb{I}$ & 0.35 \\
\hline
\end{tabular}

\section{With CIA}


Spleen, mg/g body weight

Thymus, mg

Thymus, mg/g body weight

Liver, mg

Liver, $\mathrm{mg} / \mathrm{g}$ body weight

Heart, mg

Heart, mg/g body weight

Kidney, mg

Kidney, mg/g body eight
$8.94 \pm 0.41$

$18.94 \pm 3.51$

$1.15 \pm 0.21$

$924.6 \pm 54.20$

$54.60 \pm 2.85$

$129.80 \pm 6.42$

$7.70 \pm 0.32$

$288.40 \pm 14.99$

$17.10 \pm 0.73$
$8.53 \pm 0.30$

$25.16 \pm 3.21$

$1.48 \pm 0.22$

$966.4 \pm 68.70$

$56.30 \pm 3.70$

$150.0 \pm 9.43$

$8.90 \pm 0.73$

$296.0 \pm 10.33$

$17.30 \pm 0.43$
0.17

0.1

0.16

0.33

0.36

0.04

0.08

0.35

0.429

Values are means \pm SEM; $N=9$-10/group. One mouse fed the PM-diet and immunized with collagen-died before the end of the feeding period. Means with* and $\mathbb{T}$ are significantly different from those of mice with CIA and fed the same diet; $\mathrm{p}<0.05$.

We observed no significant differences in bone mineral density and bone mineral area in mice with and without CIA by dietary treatment groups (data not shown).

Table 2. Effect of portabella mushrooms on severity of inflammation and bone erosion in micewith collagen induced arthritis (CIA) and severity of paw swelling in DBA mice.

\begin{tabular}{llll} 
& AIN 76 & PM-diet & p \\
\hline Mean scores of mononuclear cell infiltration in joints & $2.33 \pm 0.17 *$ & $2.70 \pm 0.15$ & 0.06 \\
N or \% of mice with severe mononuclear cell infiltration & $3 / 9(33.3 \%)^{*}$ & $6 / 9(66.7 \%)$ & 0.16 II \\
Mild-moderate mononuclear cell infiltration & $6 / 9(66.6 \%)$ & $3 / 9(33.3 \%)$ & \\
Mean scores of bone erosion & $1.89 \pm 0.26$ & $2.23 \pm 0.28$ & 0.18 \\
N or proportion of mice with severe bone erosion & $2 / 9(22.2 \%)$ & $4 / 9(44.4 \%)$ & 0.32 I \\
N or \% of mice with mild-moderate bone erosion & $7 / 9(78.8 \%)$ & $5 / 9(56 \%)$ & \\
\hline
\end{tabular}

*Values are means \pm SEM or percent of the group; $n=9$. Statistical tests: ANOVA and/or $\chi 2$. $\mid \chi 2$ tests were calculated using the proportion of mice with severe versus mild-to-moderate mononuclear cell infiltration and/or bone erosion.

As expected, during the first 20 days following collagen injection, no paw swelling was evident in any of the mice. Three 3 days after LPS injection, signs of CIA (i.e. paw swelling) started to appear in mice fed PM- fortified and control diets. After 4 days following LPS administration, mean CIA scores were higher in mice fed PM-fortified diet than in those fed the control diet 
(Figure 3, $\mathrm{p}<0.05$ ).

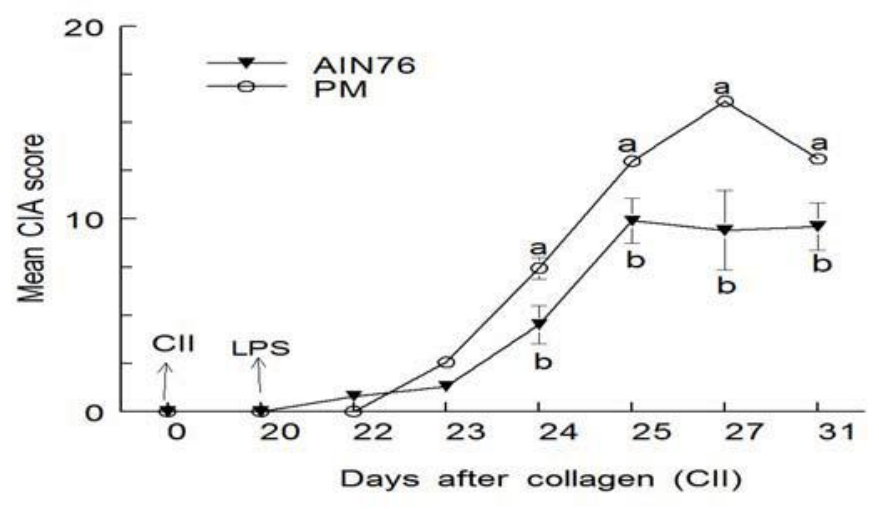

Fig 3: CIA score (index) as a function of time and in mice fed the control and PM-fortified diet. Values are means \pm SEM; $n=10$ for AIN76 and 9 for PM-fortified diet. At any time point, means with different letters are significantly different: $\mathrm{a}>\mathrm{b}, \mathrm{p}<0.05$.

In collagen-treated and untreated mice, PM significantly increased mean percent body fat and total fat mass above values obtained with the control diet ( $\mathrm{p}<005$; Table 3). However, the means of lean mass were not significantly affected by PM. The increase in fat mass explains the higher mean body weight of mice fed PM-fortified diet compared to those fed the control diet $(\mathrm{p}<0.05)$.

Table 3. Body composition as a function of diet and collagen induced arthritis (CIA) in mice.

\begin{tabular}{llll}
\hline & Control - AIN76 & PM & P \\
\hline No CIA & & & \\
\hline Lean mass, g & $15.94 \pm 1.22$ & $14.24 \pm 0.97$ & 0.15 \\
Fat mass, g & $5.10 \pm 0.34$ & $6.88 \pm 0.66$ & 0.02 \\
$\%$ fat & $25.04 \pm 0.52$ & $32.64 \pm 3.19$ & 0.02 \\
Body weight, g & $19.3 \pm 0.61$ & $20.55 \pm 0.50$ & 0.06 \\
\hline With CIA & & & \\
\hline Lean mass, g & $13.28 \pm 0.29$ & $12.83 \pm 0.60$ & 0.25 \\
Fat mass, g & $3.71 \pm 0.16$ & $4.43 \pm 0.26$ & 0.02 \\
\% fat & $21.91 \pm 0.71$ & $25.83 \pm 1.50$ & 0.01 \\
Body weight, g & $16.86 \pm 0.28$ & $17.5 \pm 0.60$ & 0.28 \\
\hline
\end{tabular}

Values are means \pm SEM. $\mathrm{N}=5$ for mice without CIA and 7-8 for those with CIA. 
In unimmunized mice, there was no significant difference in mononuclear cell distribution in joints of mice fed the control and PM-fortified diets (Figure 4A and 4B). As expected, administration of CII and LPS was associated with destruction of cartilage, bone erosion, and infiltration of inflammatory cells in the joints of mice fed control diet; and PM fortification had no protective effect on the response (Figure 4C and 4D).

\section{Effect of PM on histological changes associated with arthritis and body composition}

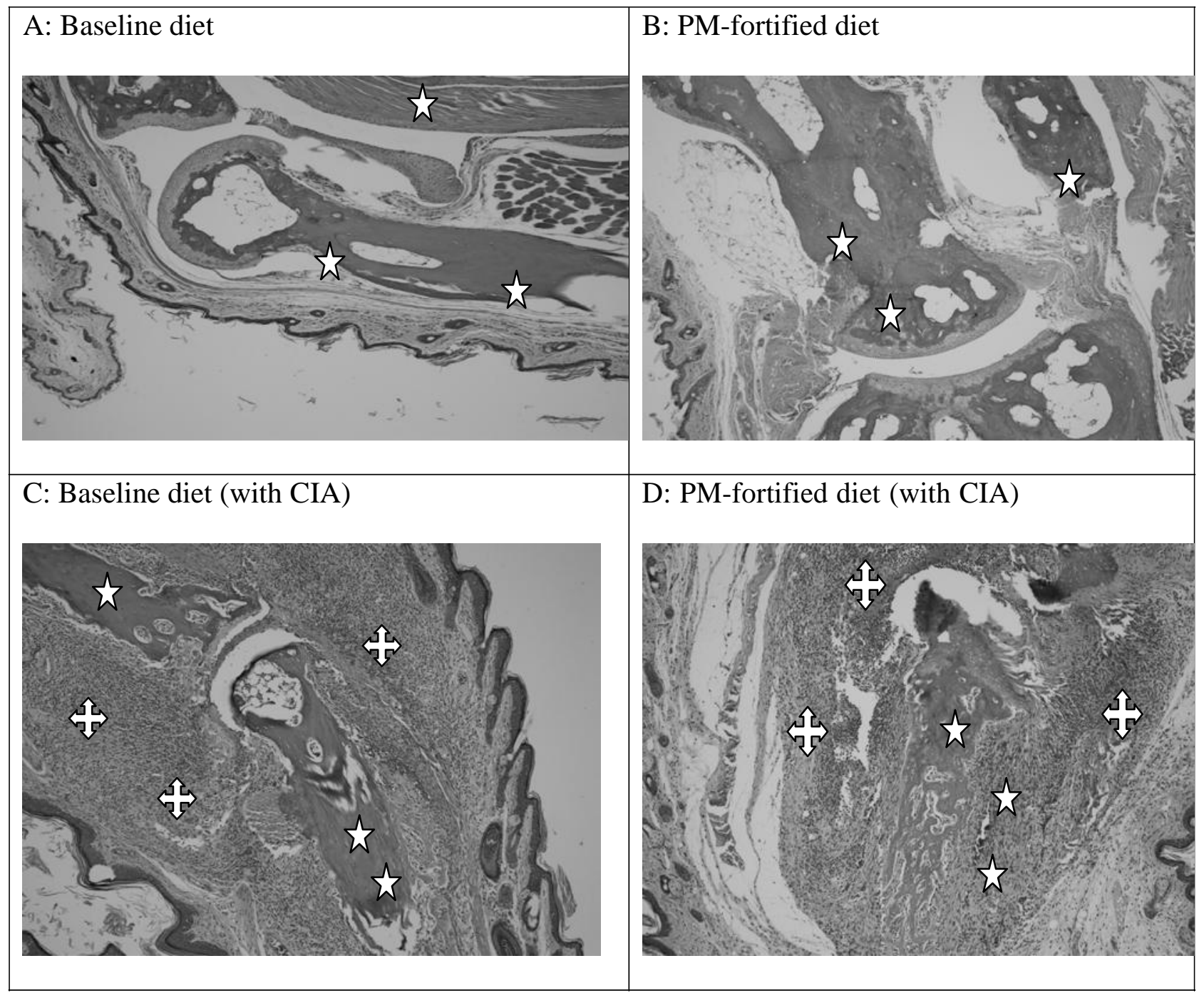

Figure 4: Histopathology of paws from mice without (A \&B) and with (C \& D) arthritis and fed baseline diet (A \& C) or PM-fortified diet (B \& D). Stars $\underset{\downarrow}{W}$ indicate bone histology, with no erosion in mice without arthritis and significant erosion, especially in structure in the joint of PM-fed mice. Crosses infiltration, which are very common in arthritis paws.

\section{Plasma and supernatant cytokine levels}


In collagen-treated and untreated mice, PM-fortification did not alter plasma levels of IL-6 and sICAM-1 since the means of neither marker were significantly different among the dietary treatment groups (Figure 5A \& B). Although PM fortification tended to reduce plasma TNF- $\alpha$ levels in control mice $(p=0.1$ ) and mice with CIA (Figure $5 \mathrm{C}, \mathrm{p}>0.1$ ), there appeared to be significant biological variation among mice within each dietary treatment.

A: IL-6

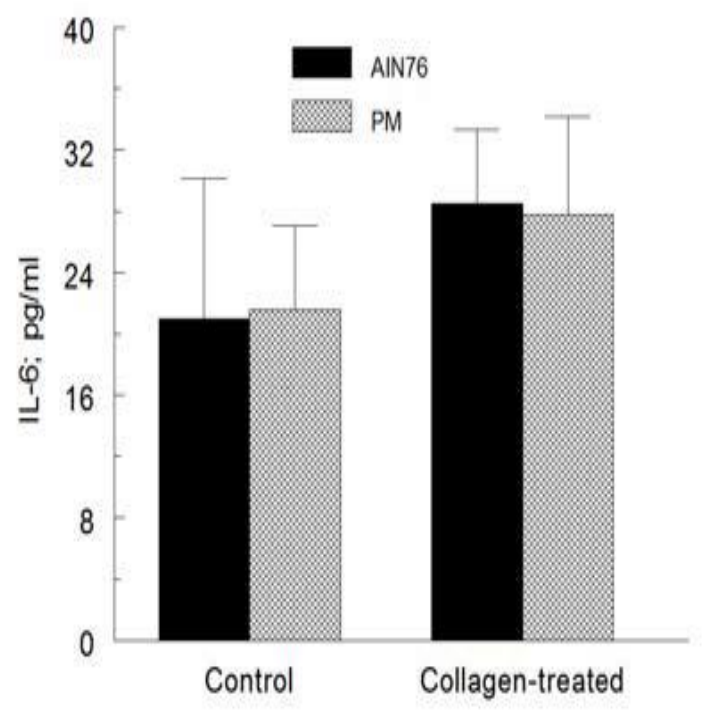

B: sICAM1

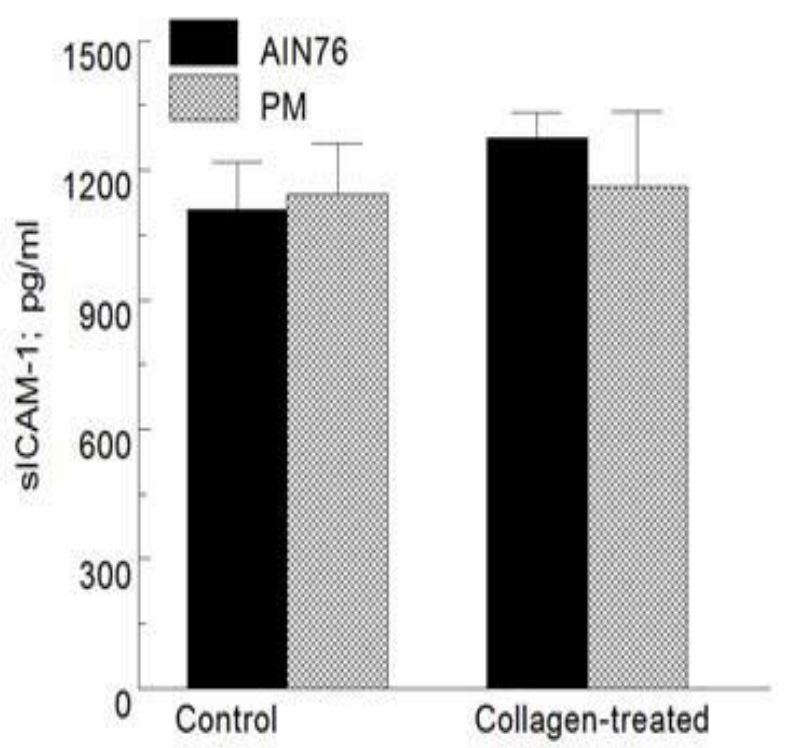

C: TNF- $\alpha$

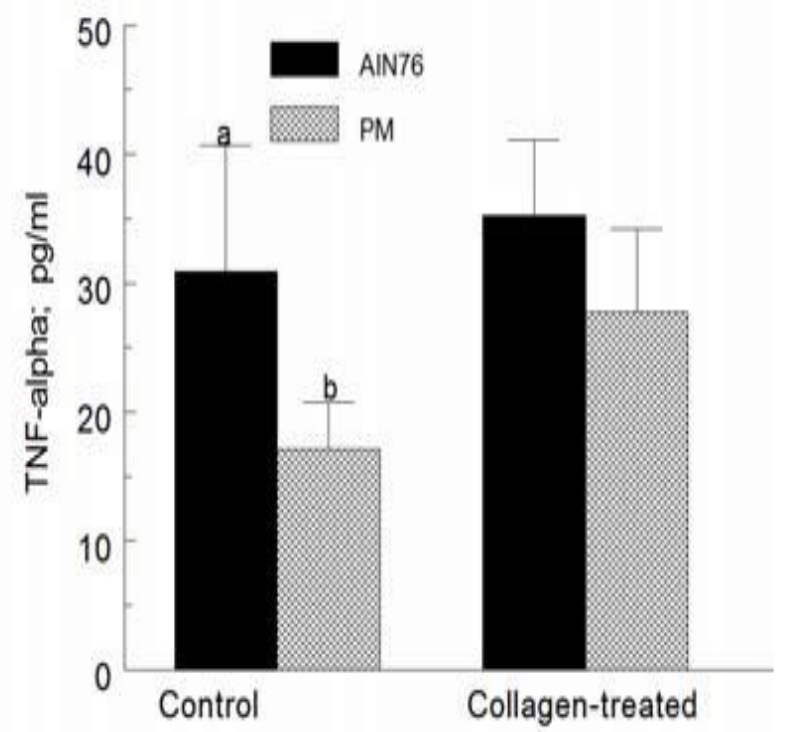

Figure 5. Plasma levels of IL-6 (A), sICAM-1 (B), and TNF- $\alpha$ (C) in collagen-treated and untreated mice fed the AIN76 and portabella mushroom (PM)-fortified diet. Values are means \pm SEM; $\mathrm{n}=8-10 ; \mathrm{a}>\mathrm{b}, \mathrm{p}=0.1$. 
In mice without and those with CIA, feeding a PM-fortified diet had no significant effect on baseline IL-6 and TNF- $\alpha$ secretion by spleen cells (Fig 6A D). In contrast to baseline cytokine levels, there were significant differences in cytokine secretion in activated cultures according to

A

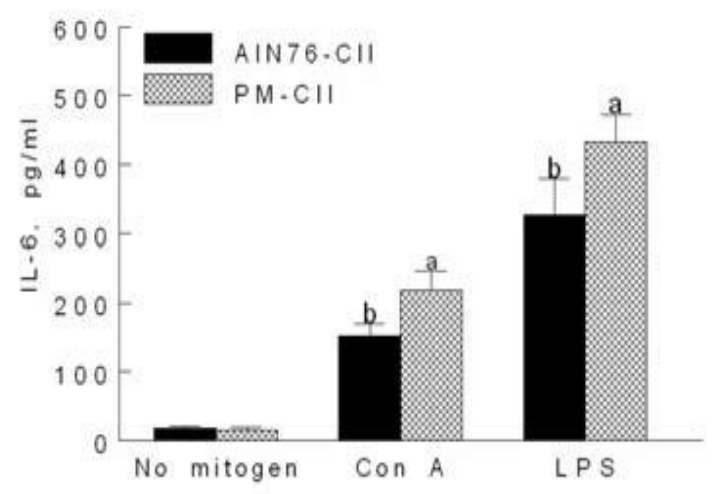

$\mathrm{C}$

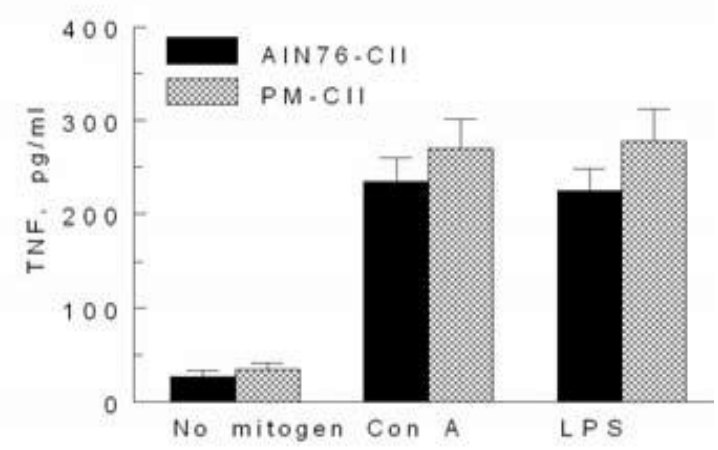

B

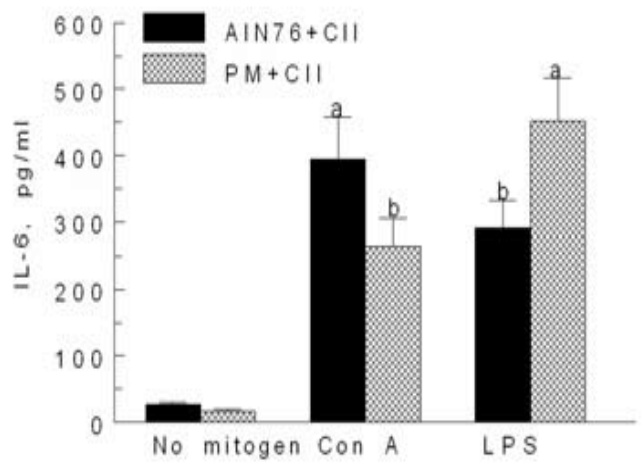

$\mathrm{D}$

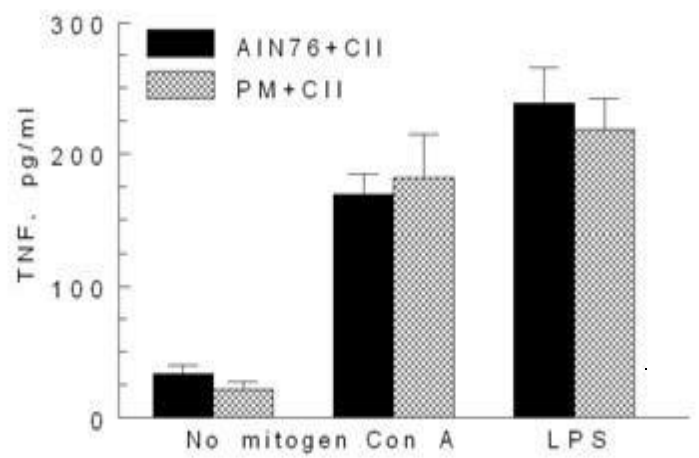

Fig 6: Cytokine concentration in supernatants of mitogen-treated and untreated spleen cells as a function of dietary treatment and collagen-induced arthritis. Values are means \pm SEM. Within each mitogen, bars with different superscript letters are significantly different; $a>b ; p<0.05$.

\section{Cell proliferation by MTT test}

In mice without and those with CIA, PM did not significantly affect cell proliferation in response to Con A and LPS, or in baseline cultures (data not shown). While collagen treatment of mice fed the control diet did not alter cell proliferation, it significantly increased the response to Con A of spleen cells obtained from mice fed PM-fortified diet ( $p<0.05$; data not shown).

\section{Correlation coefficient}

We observed no significant correlation between plasma and arthritis indices, mononuclear cell infiltration, bone erosion or cytokines levels by dietary treatment. Interestingly, while the percent body fat negatively correlated with spleen weight (control, $r=-0.552, \mathrm{PM}, \mathrm{r}=-0.595, \mathrm{p}<0.05$ ), it positively, though not significantly correlated with thymus weight. The percent body fat also 
negatively correlated with plasma IL-6 $(r=-0.758 \& \mathrm{r}=-0.534$, control and PM diets, respectively; $\mathrm{p}<0.05)$ and positively, but not significantly correlated with plasma TNF- $\alpha$.

\section{DISCUSSION:}

The main goal of this study was to assess the putative health benefits of PM on arthritis. We used an animal model of CIA in DBA1 mice, a well described model for the human arthritis. We were in particular interested in determining the effects of PM added to the AIN76 diet on the incidence of CIA, CIA index, fat and lean mass, and cytokine concentration in plasma. The rationale for conducting the study was that PM belongs to the same genius (Arigacus Bosporus) as white button mushrooms (WBM). In a recent study, we observed that WBM fortification decreased the incidence and severity of CIA, reduced plasma levels of the pro-inflammatory cytokine TNF- $\alpha$, and increased plasma concentration of the anti-inflammatory cytokine IL-6 [23]. Under the experimental conditions, our current study revealed that PM-fortification does not appear to provide protection from CIA pathogenesis. In contrast to WBM, PM did not reduce the incidence and/or the severity assessed by arthritis score, bone erosion, or mononuclear cell infiltration in joints. However, it must be noted that we only studied one dose of PM fortification, and we euthanized mice within 11-12 days after LPS injection. It should also be noted that the protocol of using LPS in lieu of a second collagen booster dose usually induce CIA in $90-100 \%$ of mice [28]. It is possible that the short follow-up period and the use of LPS prevented us for detecting a beneficial effect of PM on arthritis.

Despite the lack of reduction in CIA incidence, feeding a PM-fortified diet decreased plasma TNF- $\alpha$ levels, but increased body fat in both collagen-treated and untreated mice. The decrease in plasma TNF- $\alpha$ is in contrast to what we expected because fat cells are also a source of TNF- $\alpha$ [30]. Considering that PM had no significant effect on in vitro secretion of TNF- $\alpha$ by spleen cells (an important source of this cytokine), we speculate that PM is reducing TNF- $\alpha$ in fat cells rather than immune cells. The effect of PM extracts on in vitro secretion of TNF- $\alpha$ will be the focus of our next study. Assuming that the observations made in mice are also true in humans, reduced plasma levels of TNF- $\alpha$ would suggest that PM may modulate inflammatoryinduced chronic diseases [31].

Related to lean body mass, PM had two beneficial effects. First, following CIA induction, PM resulted in enhanced loss of fat mass $(35.6 \%$ vs $27.3 \%$ in mice fed the control diet) compared to unimmunized mice. Second, PM-fortification repressed loss of lean body mass ( $10 \%$ vs $16.69 \%$ ) due to CIA. These observations may imply that consumption of PM may protect animal models or subjects with arthritis from cachexia usually associated with this disease. The protection may be attributed in part to decreased plasma TNF- $\alpha$ levels as shown in Figure 5 and as expected from published reports [12]. Another important point on the possible beneficial effects of PM is that, although CIA induced thymus atrophy in mice fed both diets, PM appeared to attenuate thymus atrophy. For example, the difference between collagen-treated and untreated mice was $20.78 \%$ for PM-fed mice vs $47.82 \%$ in AIN-76 fed mice. Protection of the thymus would result in preservation of $\mathrm{T}$ cell numbers and perhaps function in mice or subjects consuming PM versus baseline diet.

Both TNF- $\alpha$ and IL-6 have been shown to play crucial roles in CIA and/or arthritis in humans [3-5;32-37]. Not only elevated levels are observed in the synovial tissues (fluid) and 
plasma, but also improvement of arthritis symptoms following drug therapy is associated with decreased synovial and/or plasma cytokine levels. It has been shown that injection of anti-TNF antibodies to mice with CIA reduced mononuclear cell infiltration into synovial joints and various markers associated with CIA including VCAM-1, VLA-4, IL-1 $\beta$ [35]. Administration of anti-TNF- $\alpha$ antibodies after CIA onset also attenuated disease progression [36]. The expression of a more severe disease in PM-fed mice despite decreased TNF- $\alpha$ plasma levels may in part be related to IL-6. In our previous study [23], WBM and shiitake mushrooms increased plasma IL-6 and decreased TNF- $\alpha$ and attenuated the incidence and/or severity of CIA [23]. This inverse relationship suggested that IL-6 likely played the role of anti-inflammatory cytokine to reduce TNF- $\alpha$ levels and hence severity of CIA. This view is supported by published data showing that IL-6 inhibits the proliferation of fibroblastic cells from patients with rheumatoid arthritis, whereas TNF- $\alpha$ it induces fibroblast cell proliferation [38]. Synovial cell proliferation is one of the characteristics of rheumatoid arthritis. In the current study, although plasma TNF- $\alpha$ slightly decreased in mice fed PM-fortified diet, there was no significant effect on IL-6. The lack of increase in IL-6 could explain the lack of beneficial effect of PM in this CIA model. Our current results on decreased plasma TNF- $\alpha$ levels in mice fed mushroom fortified diets agree with those that we previously reported with WBM (Agaricus bisporous) [23].

In regard to cytokine secretion, the in vivo response did not fully agree with the in vitro response. In collagen unimmunized mice, PM tended to increase in vitro secretion of IL-6 and TNF- $\alpha$ in response to Con A and LPS. In mice with CIA, while PM had no significant effect on in vitro TNF- $\alpha$ secretion, it increased IL-6 in response to LPS. However, PM decreased IL-6 secretion in response to Con A. The discrepancy in IL-6 secretion in response to Con A versus LPS can be explained by the fact that Con $\mathrm{A}$ is a $\mathrm{T}$ cell mitogen whereas LPS is a monocyte/macrophages and B cell mitogen. In certain strains of mice, the percentage of B cells in the spleen is at least $50 \%$ and is higher than that of T cells [39-40]. Besides T cells, IL-6 is also secreted by monocytes, macrophages, B cells, and smooth muscle cells such as those found in blood/blood vessels [15]. When spleen cells are incubated with Con A, only $\mathrm{T}$ cells are activated and secrete IL-6. In contrast, when spleen cells are activated by LPS, B cells and macrophages secrete IL-6.

T cells may also secrete IL-6 in response to LPS via the following production cytokine cascade: activated macrophages secrete IL-12, which in turn activate T lymphocytes, which in turn lead to the secretion of various cytokines including IL-6 [40]. We speculate that the higher IL-6 secretion in LPS-treated cells derived from collagen and LPS-treated mice is due to an effect on multiple cell types as compared to $\mathrm{T}$ cells only for Con A. Since IL-6 is antiinflammatory cytokine known to down-regulate TNF- $\alpha$ secretion, the inverse relationship between IL- 6 and TNF- $\alpha$ in the supernatant of LPS-treated cells of CIA mice is therefore not surprising (Fig 6B and D).

Under the experimental conditions utilized in this study, our data revealed that PM did not affect plasma sICAM-1. This observation suggests that sICAM-1 may not be as important as TNF- $\alpha$ and IL-6 in our model. Splenomegaly and cardiomegaly observed in CIA mice may be related to anemia of chronic disease which is very common in subjects with arthritis [41]. Although we did not measure hemoglobin, increased spleen and heart weights may be related to 
the anemia of chronic inflammation. Unlike the human rheumatoid arthritis that leads to osteoporosis, there were no significant effect of CIA with and without PM on bone mineral density and bone mineral content very likely in part due to the short follow-up period of mice with CIA.

Induction of CIA was not associated with increased body fat, but rather a decrease. This is very likely due to the fact that injection of LPS is known to alter food intake as we observed in the current study, and induces energy deficits and lipolysis [42].

In summary, this study demonstrates the following findings: (a) PM did not decrease CIA incidence and/or severity assessed by paw edema, bone erosion and mononuclear cell infiltration in joints; (b) PM was associated with higher absolute and relative body fat and attenuated thymus atrophy after CIA induction; and (c) PM decreased plasma levels of TNF- $\alpha$, but not IL-6 and sICAM-1. Another important observation is that CIA induced cardiomegaly, splenomegaly, thymus atrophy, and weight loss in mice regardless of dietary treatments. Our study has three limitations, which include the short follow-up period, the use of LPS instead of a second collagen dose, and lack of cytokine measurements in the synovial fluid. In conclusion, it appears that various types of mushrooms may have different effects on arthritis pathogenesis, with portabella and maitake polysaccharides having no beneficial effect [21], while white button mushrooms, shiitake mushrooms, and Phelinus linteus having a protective effect [20]. Differences among mushrooms may be related to $\beta$-glucan structure (1,3 and 1,6 branching); however, further studies are needed to address this issue.

\section{Acknowledgements}

The authors would like to thank JM Mushrooms (Miami, OK) and Franklin Mushrooms in (CT) for their generosity of providing us with the mushrooms used in the study; and Dr. S. Pincus for his suggestions during the preparation of this manuscript. We also acknowledge financial support from The Mushroom Council, the USDA (Grant \#580790706), and Oklahoma State University.

Competing interests: Neither the first author, nor the co-authors have any conflict of interest and have no investment with the funding agencies. All authors were provided with a copy of the manuscript and approved it.

Authors' Contributions: All authors contributed to the work equally.

\section{REFERENCES:}

1. Louie SG, Park B, Yoon H. Biological response modifiers in the management of rheumatoid arthritis. Am J Health Syst Pharm 2003; 60: 346-355.

2. Kinne RW, Brauer R, Stuhlmüller B, Palombo-Kinne E, Burmester GR. Macrophages in rheumatoid arthritis. Arthritis Res 2000; 2: 189-202.

3. Cope AP. T cells in rheumatoid arthritis. Arthritis Research \& Therapy 2008; 10(Suppl1), S1(doi:10.1186/ar2412).

4. Fournier C. Where do T cells stand in rheumatoid arthritis? Joint Bone Spine 2005; 72: 527-532.

5. Majithia V, Geraci SA. Rheumatoid arthritis: diagnosis and management. Am J Med 2007; 
120 (11): 936-9.

6. Weyand CM \& Goronzy JJ. Pathogenesis of rheumatoid arthritis. Med Clin North Am 1997; 81(1): 29-55.

7. Westhovens R, Nijs J, Taelman V, Dequeker J. Body composition in rheumatoid arthritis. Br J Rheumatol 1997; 36: 444-448.

8. Book C, Karlsson KM, Akesson K, Jacobsson LTH. Early rheumatoid arthritis and body composition. Rheumatol 2009; 48: 1128-1132.

9. Nurmphamed MT. Cardiovascular risk in rheumatoid arthritis. Autoimmunity Reviews 2009; 8: 663-667.

10. Najanjo A, Sokka T, Descalzo MA, Calvo-Alen J, Horslev-Petersen K, Luukkainen RK, et al. Cardiovascular disease in patients with rheumatoid arthritis: results from the QUESTRA study. Arthritis Res \& Therapy 2008; 10:R3 (doi:10.1186/ar2383.

11. Lagrand MK, Visser CA, Hermens WT, Niessen HWM, Verheugt FWA, Wolbink GJ, Hack CE (1999) C-reactive protein as a cardiovascular risk factor: More than an epiphenomenon? Circulation 1999; 100: 96-102.

12. Brenner DA, Buck M, Fitelberg SP, Chojkler M. Tumor necrosis factor- $\alpha$ inhibits albumin gene expression in a murine model of cachexia. J Clin Invest 1990;85: 248-255.

13. Anthony DD, Haqqi TM. Collagen-induced arthritis in mice: an animal model to study the pathogenesis of rheumatoid arthritis. Clin Exp Rheumatol 1999; 17: 240-244.

14. Kannan K, Ortmann RA, Kimpel D. Animal models of rheumatoid arthritis and their relevance to human disease. Pathophysiol 2005; 12: 167-181

15. Tissi L, Puliti M, Barluzzi R, Orefici G, von Hunolstein C, Bistoni F. Role of tumor necrosis factor alpha, interleukin-1 $\beta$, and interleukin-6 in a mouse model of Group B Streptococcal arthritis. Infection \& Immunity 1999; 67(9): 4545-4550.

16. Sebba A. Tocilizumab: The first interleukin-6-receptor inhibitor. Am J Health Syst Pharm 2008; 65: 1413-1418.

17. Keane J. TNF-blocking agents and tuberculosis: new drugs illuminate an old topic. Rheumatology 2005; 44: 714-720.

18. Borcher AT, Keen CL, Gershwin ME. Mushrooms, tumors, and immunity: an update. Exp Biol Med 2004; 229: 393-406.

19. Lull C, Wichers HJ, Savelkoul HFJ. Anti-inflammatory and immunomodulating properties of fungal metabolites. Mediators of Inflam 2, 63-80.

20. Wasser SP. Medicinal mushrooms as a source of antitumor and immunomodulating polysaccharides. Appl Microbiol Bacteriol 2002; 60: 258-274.

21. Kim GY, Kim SH, Hwang SH, Kim HY, Park YM, Park SK, Lee MK, Lee SH, Lee TH, Lee JD. Oral administration of proteoglycan isolated from Phelinus linteus in the prevention and treatment of collagen-induced arthritis in mice. Biol Pharm Bull 2003; 26(6): 823-831.

22. Shigesue K, Kodama N, Namba H. Effects of Maitake (Grifola frondosa) polysaccharide on collagen-induced arthritis in mice. Jpn J. Pharmacol 2000; 84: 293-300.

23. Chandra CL, Alexander H, Traore D, Lucas EA, Clarke SL, Smith BJ, Lightfoot S, Kuvibidila S. White button and shiitake mushrooms reduce incidence and severity of 
collagen-induced arthritis in dilute brown non-agouti mice. J Nutr 2010; 141: 131-136.

24. Report of the American Institute of Nutrition Ad Hoc Committee on Standards for Nutritional Studies. J Nutr 1977; 107: 1340-48

25. Joosten et al; scoring system for severity Joosten LA, Helsen MM, van de Loo FA, van en Berg WB. Anticytokine treatment of established type II collagen-induced arthritis in DBA/1 mice. A comparative study using anti-TNF alpha, anti-IL-1 alpha/beta, and IL1Ra. Arthritis Rheum 1996; 39(5): 797-809.

26. van Vollenhoven RF. Sex differences in rheumatoid arthritis: more than meets the eye. BMC Medicine 2009; 7:12; doi:10.1186/174-7015-7-12

27. Caccese RG, Zimmermaan and Carlson RP (1992) Bacterial lipopolysaccharide potentiates type II collagen-induced arthritis in mice. Mediators of Inflam 1992; 1: 273-279.

28. Yoshino S, Sasatomi E, Mori Y, Sagai M. Oral administration of lipopolysaccharide exacerbates collagen-induced arthritis in mice. J Immunol 1999; 163: 3417-3422.

29. Kuvibidila S, Baliga BS, Gardner R, Yu L, Warrier RP, Velez M, Ode D, Haynes J (2005) Differential effects of hydroxyurea and zileuton on interleukin-13 secretion by activated murine spleen cells: Implication on the expression of vascular cell adhesion molecule-1 and pain crisis in sickle cell anemia. Cytokine, 30, 213-218.

30. Morin CL, Pagliassotti MJ, Windmiller D, Eckel RH. Adipose tissue-derived tumor necrosis factor- $\alpha$ activity is elevated in older rats. J Gerontol: Biol Scie 1997; 52A(4), B190-B195.

31. Calin Popa C, Netea MG, van Riel PLCM, van der Meer JWM, Stalenhoef AFH. The role of TNF- $\alpha$ in chronic inflammatory conditions, intermediary metabolism, and cardiovascular risk. J Lipid Res 2007;48: 751-762.

32. Alonzi T, Fattori E, Lazzaro D, Costa P, Probert L, Kollias G, De Benedetti F, Poli V, Ciliberto G. Interleukin-6 is required for the development of collagen-induced arthritis. J Exp Med 1998; 187(4): 461-468.

33. De Hooge AS, Van de Loo FAJ, Arntz OJ,Van den Berg WB. Involvement of IL-6, apart from its role in immunity, in mediating a chronic response during experimental arthritis. Am J Pathol 2000; 157: 2081-2091.

34. Thornton S, Duwel LE, Boivin GP, Ma Y, Hirsch R. Association of the course of collageninduced arthritis with distinct patterns of cytokine and chemokine messenger RNA expression. Arthritis \& Rheumatism 1999; 42(6): 1109-1118.

35. Marinova-Mutafchieva L, Williams RO, Mauri C, Mason LJ, Walmsley MJ, Taylor PC, Feldmann M, Maini RN (2000) A comparative study into the mechanisms of action of anti-tumor necrosis factor- $\alpha$, anti-CD4, and combined anti-tumor necrosis factor alpha/anti-CD4 treatment in early collagen-induced arthritis. Arthritis \& Rheumatism 2000; 43: 638-644.

36. Butler DM, Malfait AM, Maini RN, Brennan FM, Feldmann M (1999) Anti-IL-12 and anti-TNF antibodies synergistically suppress the progression of murine collagen-induced arthritis. Eur J Immunol 1999;29: 2205-2212.

37. Liang B, Song Z, Wu B, Gardner D, Shealy D, Song YX, Wooley PH (2009) Evaluation of anti-IL-6 monoclonal antibody therapy using murine type II collagen-induced arthritis. J 
Inflam 2009; 6: 10 (1-12) doi:10.1186/1476-9255-6-10.

38. Nishimoto N, Ito A, Ono M, Tagoh H, Matsumoto T, Tomita T, Ochi T, Yoshizaki K. IL-6 inhibits the proliferation of fibroblastic synovial cells from rheumatoid arthritis patients in the presence of soluble IL-6 receptor. Intern Immunol 2000; 12(2):187-193.

39. Kuvibidila S, Dardenne M, Savino W, and Lepol Francoise (1990) Influence of iron deficiency anemia on selected thymus functions in mice: thymulin biological activity, Tcell subsets, and thymocyte proliferation. Am J Clin Nutr 51, 228-232.

40. Abbas AK, Litchman AH, Pober JS. In "Cellular and Molecular Immunology"; Third Edition; WB Saunders Company, Philadelphia, 1997; page261.

41. Porter DR, Sturrock RD, Capell HA. The use of serum ferritin estimation in the investigation of anemia in patients with rheumatoid arthritis. Clin Exp Rheumatol 1994; 12(2): 179-182.

42. Steiger M, Senn M, Altreuther G, Werling D, Sutter F, Kruezer M, Langhans W. Effect off a prolonged low dose lipopolysaccharide infusion on feed intake and metabolism in Heifers. J Anim Scie 1999; 77:2523-2532. 